\title{
Minireview
}

nephron

Clinical

Practice

Published online: January 4, 2014

DOI: $\underline{10.1159 / 000357433}$

\section{Optimising Treatment of End-Stage Renal Disease in the Elderly}

\author{
Albert Power Edwina Brown \\ Imperial College Renal and Transplant Centre, Hammersmith Hospital, London, UK
}

\section{Key Words}

Conservative management - Dialysis - Elderly - End-stage

renal disease

\begin{abstract}
The features of ageing complicate the management of endstage renal disease. These complicate all dialysis modalities and will greatly affect the ability to cope with interventional treatments and quality of life. The presence of other illnesses and comorbidity associated with kidney disease mean that many patients have a poor prognosis. It is therefore important to consider the impact of dialysis on lifestyle and whether survival will actually be improved for frail older patients. This review article considers how haemodialysis and peritoneal dialysis can be adjusted for older patients, and, in particular, how the use of assistance makes peritoneal dialysis more feasible. Most importantly, older patients should be given realistic information about their prognosis and how they can cope with different treatment options, and then they should be involved in the decisions about their management.

(c) 2014 S. Karger AG, Basel
\end{abstract}

\section{Background}

It is not surprising that the dialysis population is ageing given the ageing general population and the fact that chronic kidney disease prevalence increases with age. In the UK, the dialysis population of adults aged $\geq 65$ years grew by $29 \%$ from 2005 to 2008 compared to only $16 \%$ in those aged 18-65 years $[1,2]$. In the USA from 2005 to 2008 , the highest growth rate was seen in the oldest old ( $\geq 85$ years) [3]. Dialysis for the older and frailer individual is a comparatively new treatment option. As late as 1984, Challah et al. [4] reported from a survey that $45 \%$ of a sample of UK nephrologists would decline dialysis in a 50-year-old man with ischaemic heart disease. Less than 20 years later outcomes of octogenarians on dialysis were being published [5]. This first major report of outcomes in the 'old elderly' focused on survival as the outcome measure with a median survival of 28.9 months. More recent papers have focused on physical function as well as survival. Longitudinal data of 97 patients $>80$ years from Toronto showed that whereas $75 \%$ of patients at the start of dialysis were functionally independent and living at home, within 6 months 30\% required community support or transfer to a nursing home. At 12 months only

Dr. Albert Power

Room 5N8A, Commonwealth Building, Hammersmith Campus Imperial College London

Du Cane Road, London W12 0NN (UK)

E-Mail albert.power@nhs.net 
$22 \%$ of this cohort were still alive and independent [6]. Of 3,700 nursing home residents starting haemodialysis (HD), only $15 \%$ were alive and had maintained their physical function at 12 months [7].

As a population, older patients with advanced chronic kidney disease have a tendency to present later for dialysis [8], have a higher number of comorbid conditions, are at higher risk of cognitive dysfunction [9] and have increased levels of frailty [10], all combined with potential sensory impairments such as declining vision [11]. Nutrition is also often a major problem for these patients. All these factors make any treatment modality difficult for older patients with end-stage renal disease (ESRD). Although age itself is no longer a contraindication to transplantation and access to transplantation for the elderly has increased over time [12], the majority will have too much comorbidity to be eligible, or will develop complications precluding transplantation while waiting for a kidney. Most older patients on renal replacement therapy are therefore on dialysis for the remainder of their life. With appropriate education many older patients prefer a home-based treatment, with around $60 \%$ choosing peritoneal dialysis (PD) [13]. ERA-EDTA registry data, in contrast, show that in comparison to patients aged 20-44 years, those $\geq 70$ years old are $56 \%$ less likely to receive PD as compared to HD [14]. In 2009, according to UK Renal Registry data, $26.9 \%$ of patients starting dialysis $<65$ years of age were on PD, but only $14.2 \%$ of those $\geq 65$ years [2]. This relatively low use of PD in the elderly occurs despite the obvious advantages for the fit and frail older person. For the fit elderly, PD enables travel, an active social life, continuing working, care for grandchildren, etc. The frail elderly often tolerate HD poorly because of haemodynamic instability and require transportation to and from dialysis. PD can avoid these difficulties.

Therefore, there is an urgent need to improve treatment of ESRD in the elderly. In this review, we shall focus on some specific areas which may improve the patient experience for older patients on dialysis, namely choice of dialysis modality, HD treatment, development of assisted PD (aPD) and transplantation. Finally, we shall consider the choice not to have dialysis, i.e. conservative care. As already discussed, outcomes on dialysis for older patients with multiple comorbidities are often very poor and it can appear that being on dialysis is extending the period of dying rather than providing any improvement in quality of living. It is therefore not surprising that there is a debate whether dialysis should be considered in very frail individuals [15].

Optimising ESRD in the Elderly

\section{Quality of Life and Dialysis Modality}

Remarkably, there are only two studies comparing quality of life (QoL) on HD and PD: the North Thames Dialysis Study $[16,17]$ and Broadening Options for LongTerm Dialysis in the Elderly (BOLDE) [18]. The North Thames Dialysis Study was carried out in the late 1990s when $40 \%$ of the patients were on PD in the UK; it was a prospective study of incident and prevalent patients starting on dialysis over the age of 70 years and showed that outcomes - survival and QoL - were not different for patients on HD and PD. BOLDE is a recently completed study in the same UK centres, the first part of which has focused on QoL. The principal aim of the study is to enable older patients to receive the dialysis modality of their choice. As there was so little literature about QoL, the first part of the study determined QoL, depression, symptoms and illness intrusion in older ( $\geq 65$ years) patients [18]. Seventy PD patients were compared to HD patients matched by age, gender, length of time on dialysis, ethnicity and socioeconomic status. The QoL measures used were the SF-12, Hospital Anxiety and Depression Scale and the Illness Intrusiveness Ratings Scale. After regression analyses, modality was found to be an independent predictor only of illness intrusion with greater intrusion felt in those on HD. BOLDE has therefore shown that older patients can successfully manage $\mathrm{PD}$ and that in two closely matched demographic groups of older dialysis patients on PD and HD, QoL was similar, but with significantly less perception of illness intrusion in the PD group.

\section{Modality Education and Choice}

As we have discussed above, many older patients could be eligible for home dialysis options, particularly if assistance is available. During the pre-dialysis phase while in nephrology clinics, they should have been provided with education to enable them to participate in the decision regarding the most appropriate dialysis modality for them. If we consider the wider context of governmental goals for encouraging health benefits for the UK population, involvement in treatment decisions is certainly a focal point [19]. The choice of dialysis modality is a prime example where shared decision-making should result in the patient's personal values being matched with the medical characteristics of the treatment in order to maximise achievable QoL [20]. Even in locations where dialysis modality options exist, these may not always be presented in an appropriate manner to the older patient.

Nephron Clin Pract 2013;124:202-208 
Written information from renal units is often complex and difficult to understand [21], hindering decisionmaking in a group already vulnerable to comprehension errors [22] and low healthcare literacy [23]. Increasing age has also been found to be associated with fear that home-based treatments were substandard compared to in-centre dialysis in a sample of HD patients [24]. It is therefore not surprising that some older people are more likely to prefer the healthcare team to make treatment decisions although there is wide variation in this [25]. There is also evidence that healthcare teams will respond by taking dialysis treatment decisions on behalf of older patients [26]. There is therefore a real risk within this patient group that the modality favoured by the renal team becomes the treatment of choice.

In addition to facilitating the choice of modality and ensuring timely dialysis access placement, the purpose of dedicated pre-dialysis care is to optimise the patient physically as well as psychosocially for their period of time on renal replacement therapy. For example, medicine management with tailored prescription is advisable to avoid unnecessary polypharmacy and its attendant hazards [27]. Judicious erythropoietin dosing as part of anaemia management could help in reducing stroke incidence in a population at the highest risk [28]. Dialysis initiation in the elderly is associated with a progressive loss of functional independence, which is particularly marked in nursing home residents [7, 29]. Appropriate multidisciplinary symptom management can lead to preservation of functional ability and also avoid unnecessarily early dialysis initiation for non-uraemic symptomatology [27, 30]. Individualised nutritional and dietetic interventions coupled with physiotherapy regimes may lead to better functional status and core strength over time, reduce the incidence of falls and improve well-being in a particularly vulnerable group of people [31,32]. Although there are no trial data to support the use of such preparatory interventions, achieving an optimal physical and psychological state may influence the timing of dialysis initiation especially in the frail elderly who stand to benefit the most.

\section{Haemodialysis}

European registry data demonstrates that patients aged $>70$ years are $56 \%$ less likely to start with PD compared to HD which remains the dominant modality in elderly patients [14], reaching $86 \%$ of incident patients aged $\geq 65$ years in the UK [33]. It is therefore important to understand the direct impact this treatment has on the physical and psychosocial health of older people and how clinical practice can be improved.

The elderly on HD represent a physically frail patient group with multiple comorbid conditions and functional dependencies. In a recent report from the Dialysis Outcomes and Practice Patterns Study (DOPPS), 46-55\% of patients aged $\geq 75$ years had coronary artery disease, 25 $30 \%$ cerebrovascular disease, and up to $50 \%$ had congestive cardiac failure and peripheral vascular disease [34]. Older patients are more prone to intradialytic hypotension [35], which may relate to myocardial dysfunction and impaired autonomic function [36]. The intradialytic reduction in myocardial blood flow seen during HD [37] could further worsen haemodynamic instability resulting in repeated cycles of end-organ hypoperfusion. This may underpin the heightened predisposition to falls [38, 39], cardiac events, cerebral dysfunction and stroke [40, 41], malnutrition-inflammation syndrome [42], and loss of residual renal function [43] that is seen in older HD patients. Tailored dialysis prescription using an appropriate target dry weight aided by bioimpedance analysis [44] and the use of judicious, slower, feedback-controlled ultrafiltration with lowered dialysate sodium concentrations $(<140$ $\mathrm{mmol} / \mathrm{l})$ [45] can help maintain intradialytic haemodynamic stability in conventional HD schedules. Cooled dialysate, where tolerated, can promote blood pressure stability [46], and more frequent HD regimes (e.g. short daily or nocturnal) may also be used with good effect [47]. We advise caution in the use of vasoconstrictors (e.g. midodrine) to treat symptomatic hypotension given the high prevalence of vascular disease in this population [48].

In comparison to younger populations, there is a higher prevalence of central venous catheter use in the elderly [49], an access form independently associated with a greater risk of death [50]. Although it is believed that age is a risk factor for poor maturation of arteriovenous fistulae, recent series have shown that this is not the case [51, 52], and more effort should be made to promote this form of vascular access in a group of patients that often receives less pre-dialysis care than their younger counterparts [53].

Forty percent of patients in DOPPS were unable to walk without assistance [34], and up to $75 \%$ of the elderly on dialysis fulfil criteria for frailty that itself portends an adverse prognosis [10]. The lifestyle restrictions of thrice weekly in-centre HD coupled with potentially long and arduous transport times can be significant for elderly patients and influence choice of modality [54]. Conventional HD can exacerbate functional impairment by leaving patients feeling exhausted and worn-out with a long 
'time to recovery' [55], an effect attributed to intradialytic haemodynamic changes and transient biochemical disequilibrium [56], and which can be mitigated by slow daily HD as a home-based treatment [57]. Appropriate multidisciplinary pre-dialysis education can reduce 1-year morbidity in incident patients [57] and targeted rehabilitation programmes are able to improve functional status in elderly patients with new-onset disability allowing over $70 \%$ of those affected to return to their private homes [58]. One study of 271 patients admitted to a nursing home for rehabilitation demonstrated that staffassisted HD is feasible and can allow for successful home discharge in $40 \%$ of the cases [59].

\section{Transplantation}

Transplantation remains the optimal mode of renal replacement therapy and is associated with a significant survival advantage in younger populations and improved QoL. This survival advantage is also seen in elderly ( $>70$ years) US transplant recipients compared to matched patients on a transplant waiting list $(41 \%$ reduced risk of death) [60], although this relative benefit may be less marked in countries with better dialysis survival than the US and appears to wane with increasing dialysis vintage [61]. However, older age is associated with increased comorbidity and decreased functional ability that can itself preclude transplantation. In addition, the probability of receiving a cadaveric graft declines with increasing age: only $8 \%$ of wait-listed patients aged $65-75$ years in the UK were transplanted within 5 years of listing in one study [62]. Allocation schemes such as the Eurotransplant Senior Programme have been developed to improve access to age-matched organs for patients $\geq 65$ years old and have yielded results comparable to those via conventional allocation schemes [63].

Although numerous studies have shown that older age per se does not adversely influence allograft outcomes [64], data suggest higher rates of surgical complications in elderly recipients $[65,66]$ and caution is advised regarding the intensity of immunosuppression and the attendant risk of infectious complications [67] and posttransplant malignancy [68]. There are few, heterogeneous studies examining the impact of transplantation on QoL in elderly recipients and those undergoing transplantation represent a highly selected group manifesting a degree of physical health and psychological motivation. Early and careful assessment of fitness for transplantation is required to facilitate appropriate transplant listing in the elderly. In addition, given the scarcity of donor organs, living donation should be promoted and can be both feasible and successful [69].

\section{Assisted Peritoneal Dialysis}

Realistically, few frail elderly patients will be able to perform their own PD. In some instances, family members will help, but usually, when this is not possible, patients are placed on HD with all its difficulties, and some will opt for conservative care, i.e. no dialysis. In recent years, various models of aPD have evolved to enable this group of patients to have PD in their own homes. The longest and largest experience of aPD is in France, where $\mathrm{PD}$ is predominantly a treatment of the elderly, with more than $50 \%$ of PD patients being over 70 years of age [70]. A recent analysis by the French REIN registry of 3,512 patients over 75 years starting dialysis between 2002 and 2005 showed that $18 \%$ began with PD, with the proportion varying from 3 to $38 \%$ depending on region; over half of these patients were on aPD [71]. aPD is being developed in many other parts of Europe using various models of care [72]. Experience from Toronto suggests that availability of assistance can increase the proportion of patients considered to be eligible for PD [13]. This study also showed that adverse events (e.g. hospitalisations and death) were no different between patients on aPD and other dialysis modalities in older people. There is no data about QoL or patient outcomes on aPD compared to HD; this is being addressed by the Frail and Elderly Patient Outcomes on Dialysis (FEPOD) study which will report its initial results in 2014.

\section{Conservative Care}

Given the poor outcomes of many old and frail patients with multiple comorbidities on dialysis, it is not surprising that there is a debate whether non-dialysis management would be more humane [15]. In the UK, conservative care, or maximum management without dialysis, has increasingly been offered and is not infrequently chosen by older and frail patients [73, 74]. In Australia a recent study suggests that $14 \%$ of patients with chronic kidney disease stage 5 choose conservative care; not surprisingly, this group was elderly with a median age of 80 years [75]. Such patients continue to be followed in renal clinics with active management focusing on anaemia, fluid status and symptom control. It is difficult to determine 
survival on conservative care as there is no definite start as there is with dialysis. Using a fixed GFR prior to starting dialysis as the start point, studies have suggested that there is no difference in survival of older patients with multiple comorbidities or poor physical function on conservative care and dialysis $[73,74,76]$. Indeed, there is a suggestion that some patients $>75$ years with high comorbidity could actually live longer than those on dialysis [74]. There are no studies comparing QoL on conservative care and dialysis, but recent evidence suggests that conservative care patients maintain their level of physical function for their last year of life until a sharp decline in the last month [77], in comparison to the functional decline that occurs in many frail elderly patients after starting dialysis [6,7]. Conservative care patients are also more likely to die at home or in a hospice and spend fewer days in hospital than those on dialysis [78].

\section{End-of-Life Management}

Median survival for patients $>75$ years starting on dialysis is short - around 2.5 years according to UK Renal Registry data [2]. Management of older patients with ESRD should therefore include discussions about realistic outcomes from interventions - not just dialysis, but also management of comorbidity. Patients will have different goals and attitudes to the extent of treatment they wish and this should be ascertained as part of shared decisionmaking [79]. A recent study by Schell et al. [80], however, shows that nephrologists often do not discuss prognosis with their elderly patients. The UK General Medical Council guidance on end-of-life care (2010) states that doctors must ensure that death becomes 'an explicit discussion point when patients are likely to die within 12 months, and that medical paternalism on the subject, however benignly intended, must be replaced by patient choice' [81]. For prevalent HD patients, a prognostic tool for the end-of-life phase has been developed based on five variables, namely older age, dementia, peripheral vascular disease, decreased albumin and the answer 'no' to 'would you be surprised if the patient died in the next 6 months?' [82]. Most models for transition to palliative care recommend a phased approach with a gradual change in focus from cure or active management of a chronic disease to 'supportive' management with the focus of care being on maximising QoL. This should include identifying and managing symptoms [83], including pain [84], mental health issues, particularly depression [85], and being aware of spiritual needs [86].

\section{Conclusion}

As the numbers of older people developing ESRD continue to rise, we need to evolve treatment patterns that focus on patient-orientated outcomes. This involves integration between nephrologists, medicine for the elderly and palliative care specialists, primary care in the community and social care. For too long, survival has been the main outcome measure by which we have assessed different renal replacement treatment modalities; this is easy to measure but completely ignores the QoL of the individual on that therapy. In any case, there is little evidence that there is any significant survival advantage between HD, $\mathrm{PD}$, and transplantation for older patients - and for the frail elderly, no survival advantage between dialysis and non-dialysis. Management should therefore be individualised for each patient depending on their lifestyle goals and their understanding of realistic outcomes for each treatment modality. We should move away from the default position of treatment with in-hospital HD. This denies the rights of fitter older patients to the independence associated with home treatment and can result in dramatic reduction in physical function for older frail patients. Development of assisted PD would also enable more frail patients to have their treatment at home. This approach will result in better care for our patients and will limit the use of inappropriate and futile intensive and intrusive treatments as patients approach the end of their life.

References

1 Ansell D: Summary of findings in the 2006 UK Renal Registry report (chapter 1). Nephrol Dial Transplant 2007;22(suppl 7):vii1-vii2.

-2 Byrne C, Ford D, Gilg J, Ansell D, Feehally J: UK Renal Registry 12th Annual Report (December 2009): chapter 3: UK ESRD incident rates in 2008: national and centre-specific analyses. Nephron Clin Pract 2010;115(suppl 1):c9-c39.

3 United States Renal Data System. USRDS 2010 Annual Data Report: Atlas of End-Stage Renal Disease in the United States. Bethesda, National Institutes of Health, National Institute of Diabetes and Digestive and Kidney Diseases, 2010.

4 Challah S, Wing AJ, Bauer R, Morris RW, Schroeder SA: Negative selection of patients for dialysis and transplantation in the United Kingdom. Br Med J (Clin Res Ed) 1984;288: 1119-1122.

5 Joly D, Anglicheau D, Alberti C, Nguyen AT, Touam M, Grunfeld JP, et al: Octogenarians reaching end-stage renal disease: cohort study of decision-making and clinical outcomes. J Am Soc Nephrol 2003;14:1012-1021. 
-6 Jassal SV, Chiu E, Hladunewich M: Loss of independence in patients starting dialysis at 80 years of age or older. N Engl J Med 2009; 361:1612-1613.

7 Kurella TM, Covinsky KE, Chertow GM, Yaffe K, Landefeld CS, McCulloch CE: Functional status of elderly adults before and after initiation of dialysis. N Engl J Med 2009;361: 1539-1547.

-8 Roderick P, Jones C, Drey N, Blakeley S, Webster P, Goddard J, et al: Late referral for endstage renal disease: a region-wide survey in the south west of England. Nephrol Dial Transplant 2002;17:1252-1259.

-9 Kurella M, Chertow GM, Fried LF, Cummings SR, Harris T, Simonsick E, et al: Chronic kidney disease and cognitive impairment in the elderly: the health, aging, and body composition study. J Am Soc Nephrol 2005;16: 2127-2133.

$\checkmark 10$ Johansen KL, Chertow GM, Jin C, Kutner NG: Significance of frailty among dialysis patients. J Am Soc Nephrol 2007;18:2960-2967.

11 Chiu E, Markowitz SN, Cook WL, Jassal SV: Visual impairment in elderly patients receiving long-term hemodialysis. Am J Kidney Dis 2008;52:1131-1138.

12 Schaeffner ES, Rose C, Gill JS: Access to kidney transplantation among the elderly in the United States: a glass half full, not half empty. Clin J Am Soc Nephrol 2010;5:2109-2114.

-13 Oliver MJ, Quinn RR, Richardson EP, Kiss AJ, Lamping DL, Manns BJ: Home care assistance and the utilization of peritoneal dialysis. Kidney Int 2007;71:673-678.

- 14 van de Luijtgaarden MW, Noordzij M, Stel VS, Ravani P, Jarraya F, Collart F, et al: Effects of comorbid and demographic factors on dialysis modality choice and related patient survival in Europe. Nephrol Dial Transplant 2011;26:2940-2947.

15 Knauf F, Aronson PS: ESRD as a window into America's cost crisis in health care. J Am Soc Nephrol 2009;20:2093-2097.

16 Harris SA, Lamping DL, Brown EA, Constantinovici N: Clinical outcomes and quality of life in elderly patients on peritoneal dialysis versus hemodialysis. Perit Dial Int 2002;22: 463-470.

-17 Lamping DL, Constantinovici N, Roderick P, Normand C, Henderson L, Harris S, et al: Clinical outcomes, quality of life, and costs in the North Thames Dialysis Study of elderly people on dialysis: a prospective cohort study. Lancet 2000;356:1543-1550.

- 18 Brown EA, Johansson L, Farrington K, Gallagher H, Sensky T, Gordon F, et al: Broadening Options for Long-Term Dialysis in the Elderly (BOLDE): differences in quality of life on peritoneal dialysis compared to haemodialysis for older patients. Nephrol Dial Transplant 2010;25:3755-3763.

19 Department of Health UK: Equity and Excellence: Liberating the NHS. London, HMSO, 2010.
20 Tamura MK, Tan JC, O’Hare AM: Optimizing renal replacement therapy in older adults: a framework for making individualized decisions. Kidney Int 2012;82:261-269.

21 Winterbottom A, Conner M, Mooney A, Bekker HL: Evaluating the quality of patient leaflets about renal replacement therapy across UK renal units. Nephrol Dial Transplant 2007;22:2291-2296.

22 Finucane ML, Mertz CK, Slovic P, Schmidt ES: Task complexity and older adults' decision-making competence. Psychol Aging 2005;20:71-84.

-23 Bostock S, Steptoe A: Association between low functional health literacy and mortality in older adults: longitudinal cohort study. BMJ 2012;344:e1602.

24 McLaughlin K, Manns B, Mortis G, Hons R, Taub K: Why patients with ESRD do not select self-care dialysis as a treatment option. Am J Kidney Dis 2003;41:380-385.

25 Bastiaens H, Van Royen P, Pavlic DR, Raposo V, Baker R: Older people's preferences for involvement in their own care: a qualitative study in primary health care in 11 European countries. Patient Educ Couns 2007;68:3342.

26 Orsino A, Cameron JI, Seidl M, Mendelssohn D, Stewart DE: Medical decision-making and information needs in end-stage renal disease patients. Gen Hosp Psychiatry 2003;25:324331.

27 Rosansky SJ, Clark WF: Has the yearly increase in the renal replacement therapy population ended? J Am Soc Nephrol 2013;24: 1367-1370.

28 Pfeffer MA, Burdmann EA, Chen CY, Cooper ME, de Zeeuw D, Eckardt KU, et al: A trial of darbepoetin alfa in type 2 diabetes and chronic kidney disease. N Engl J Med 2009;361: 2019-2032.

29 Jassal SV, Watson D: Dialysis in late life: benefit or burden. Clin J Am Soc Nephrol 2009;4: 2008-2012.

30 Schmidt RJ: Informing our elders about dialysis: is an age-attuned approach warranted? Clin J Am Soc Nephrol 2012;7:185-191.

31 Farragher J, Jassal SV: Rehabilitation of the geriatric dialysis patient. Semin Dial 2012;25: 649-656.

32 Kolewaski CD, Mullally MC, Parsons TL, Paterson ML, Toffelmire EB, King-VanVlack CE: Quality of life and exercise rehabilitation in end stage renal disease. CANNT J 2005;15: $22-29$.

33 Gilg J, Castledine C, Fogarty D, Feest T: UK Renal Registry 13th Annual Report (December 2010): chapter 1: UK RRT incidence in 2009: national and centre-specific analyses. Nephron Clin Pract 2011;119(suppl 2):c1c25.

- 34 Canaud B, Tong L, Tentori F, Akiba T, Karaboyas A, Gillespie B, et al: Clinical practices and outcomes in elderly hemodialysis patients: results from the Dialysis Outcomes and Practice Patterns Study (DOPPS). Clin J Am Soc Nephrol 2011;6:1651-1662.
35 Tisler A, Akocsi K, Harshegyi I, Varga G, Ferenczi S, Grosz M, et al: Comparison of dialysis and clinical characteristics of patients with frequent and occasional hemodialysis-associated hypotension. Kidney Blood Press Res 2002;25:97-102.

36 Di LR, Vita G, Messina C, Savica V: Autonomic function in elderly uremics studied by spectral analysis of heart rate. Kidney Int 2005;67:1521-1525.

37 Dasselaar JJ, Slart RH, Knip M, Pruim J, Tio RA, McIntyre CW, et al: Haemodialysis is associated with a pronounced fall in myocardial perfusion. Nephrol Dial Transplant 2009;24: 604-610.

38 Abdel-Rahman EM, Turgut F, Turkmen K, Balogun RA: Falls in elderly hemodialysis patients. QJM 2011;104:829-838.

39 Desmet C, Beguin C, Swine C, Jadoul M: Falls in hemodialysis patients: prospective study of incidence, risk factors, and complications. Am J Kidney Dis 2005;45:148-153.

40 Pereira AA, Weiner DE, Scott T, Chandra P, Bluestein R, Griffith J, et al: Subcortical cognitive impairment in dialysis patients. Hemodial Int 2007;11:309-314.

-41 Power A, Chan K, Singh SK, Taube D, Duncan N: Appraising stroke risk in maintenance hemodialysis patients: a large single-center cohort study. Am J Kidney Dis 2012;59:249257.

$\checkmark 42$ Kotanko P, Carter M, Levin NW: Intestinal bacterial microflora - a potential source of chronic inflammation in patients with chronic kidney disease. Nephrol Dial Transplant 2006;21:2057-2060.

43 Perl J, Bargman JM: The importance of residual kidney function for patients on dialysis: a critical review. Am J Kidney Dis 2009;53: 1068-1081.

44 Raimann J, Liu L, Ulloa D, Kotanko P, Levin NW: Consequences of overhydration and the need for dry weight assessment. Contrib Nephrol. Basel, Karger, 2008, vol 161, pp 99107

45 Coli L, La Manna G, Comai G, Ursino M, Ricci D, Piccari M, et al: Automatic adaptive system dialysis for hemodialysis-associated hypotension and intolerance: a noncontrolled multicenter trial. Am J Kidney Dis 2011;58: 93-100.

46 Selby NM, McIntyre CW: A systematic review of the clinical effects of reducing dialysate fluid temperature. Nephrol Dial Transplant 2006;21:1883-1898.

47 Cornelis T, Kotanko P, Goffin E, Kooman JP, van der Sande FM, Chan CT: Can intensive hemodialysis prevent loss of functionality in the elderly ESRD patient? Semin Dial 2011;24: 645-652.

48 Rubinstein S, Haimov M, Ross MJ: Midodrine-induced vascular ischemia in a hemodialysis patient: a case report and literature review. Ren Fail 2008;30:808-812. 
-49 Ethier J, Mendelssohn DC, Elder SJ, Hasegawa T, Akizawa T, Akiba T, et al: Vascular access use and outcomes: an international perspective from the Dialysis Outcomes and Practice Patterns Study. Nephrol Dial Transplant 2008;23:3219-3226.

-50 Desilva RN, Sandhu GS, Garg J, GoldfarbRumyantzev AS: Association between initial type of hemodialysis access used in the elderly and mortality. Hemodial Int 2012;16:233241.

-51 Jennings WC, Landis L, Taubman KE, Parker DE: Creating functional autogenous vascular access in older patients. J Vasc Surg 2011;53: 713-719.

-52 Smith GE, Gohil R, Chetter IC: Factors affecting the patency of arteriovenous fistulas for dialysis access. J Vasc Surg 2012;55:849-855.

-53 Zhao Y, Brooks JM, Flanigan MJ, Chrischilles EA, Pendergast JF, Hunsicker LG: Physician access and early nephrology care in elderly patients with end-stage renal disease. Kidney Int 2008;74:1596-1602.

-54 Morton RL, Snelling P, Webster AC, Rose J, Masterson R, Johnson DW, et al: Factors influencing patient choice of dialysis versus conservative care to treat end-stage kidney disease. CMAJ 2012;184:E277-E283.

-55 Lindsay RM, Heidenheim PA, Nesrallah G, Garg AX, Suri R, Daily Hemodialysis Study Group London Health Sciences Centre: Minutes to recovery after a hemodialysis session: a simple health-related quality of life question that is reliable, valid, and sensitive to change. Clin J Am Soc Nephrol 2006;1:952-959.

-56 Arieff AI: Dialysis disequilibrium syndrome: current concepts on pathogenesis and prevention. Kidney Int 1994;45:629-635.

- 57 Wingard RL, Pupim LB, Krishnan M, Shintani A, Ikizler TA, Hakim RM: Early intervention improves mortality and hospitalization rates in incident hemodialysis patients: RightStart program. Clin J Am Soc Nephrol 2007; 2:1170-1175

58 Li M, Porter E, Lam R, Jassal SV: Quality improvement through the introduction of interdisciplinary geriatric hemodialysis rehabilitation care. Am J Kidney Dis 2007;50:90-97.

-59 Reddy NC, Korbet SM, Wozniak JA, Floramo SL, Lewis EJ: Staff-assisted nursing home haemodialysis: patient characteristics and outcomes. Nephrol Dial Transplant 2007;22: 1399-1406.

-60 Rao PS, Merion RM, Ashby VB, Port FK, Wolfe RA, Kayler LK: Renal transplantation in elderly patients older than 70 years of age: results from the Scientific Registry of Transplant Recipients. Transplantation 2007;83: 1069-1074.
61 Jassal SV, Krahn MD, Naglie G, Zaltzman JS, Roscoe JM, Cole EH, et al: Kidney transplantation in the elderly: a decision analysis. J Am Soc Nephrol 2003;14:187-196.

62 Stevens KK, Woo YM, Clancy M, McClure JD, Fox JG, Geddes CC: Deceased donor transplantation in the elderly - are we creating false hope? Nephrol Dial Transplant 2011; 26:2382-2386.

63 Fabrizii V, Horl WH: Renal transplantation in the elderly. Curr Opin Urol 2001;11:159-163.

64 Mendonca HM, Dos Reis MA, de Castro de Cintra S, Camara NO, Pacheco-Silva A: Renal transplantation outcomes: a comparative analysis between elderly and younger recipients. Clin Transplant 2007;21:755-760.

65 Bentas W, Jones J, Karaoguz A, Tilp U, Probst M, Scheuermann E, et al: Renal transplantation in the elderly: surgical complications and outcome with special emphasis on the Eurotransplant Senior Programme. Nephrol Dial Transplant 2008;23:2043-2051.

-66 Debska-Sslizien A, Jankowska MM, Wolyniec W, Zietkiewicz M, Gortowska M, Moszkowska G, et al: A single-center experience of renal transplantation in elderly patients: a paired-kidney analysis. Transplantation 2007;83:1188-1192.

67 Sommerer C, Schnitzler P, Meuer S, Zeier M, Giese T: Pharmacodynamic monitoring of cyclosporin A reveals risk of opportunistic infections and malignancies in renal transplant recipients 65 years and older. Ther Drug Monit 2011;33:694-698.

68 Cameron JS: Renal transplantation in the elderly. Int Urol Nephrol 2000;32:193-201.

69 O’Brien B, Mastoridis S, Sabharwal A, Hakim N, Taube D, Papalois V: Expanding the donor pool: living donor nephrectomy in the elderly and the overweight. Transplantation 2012;95: 1158-1165.

70 Verger C, Ryckelynck JP, Duman M, Veniez G, Lobbedez T, Boulanger E, et al: French peritoneal dialysis registry (RDPLF): outline and main results. Kidney Int Suppl 2006; 103:S12-S20.

71 Couchoud C, Moranne O, Frimat L, Labeeuw M, Allot V, Stengel B: Associations between comorbidities, treatment choice and outcome in the elderly with end-stage renal disease. Nephrol Dial Transplant 2007;22:3246-3254.

72 Brown EA, Dratwa M, Povlsen JV: Assisted peritoneal dialysis - an evolving dialysis modality. Nephrol Dial Transplant 2007;22: 3091-3092.

73 Murtagh FE, Marsh JE, Donohoe P, Ekbal NJ, Sheerin NS, Harris FE: Dialysis or not? A comparative survival study of patients over 75 years with chronic kidney disease stage 5 . Nephrol Dial Transplant 2007;22:1955-1962.

74 Chandna SM, Da Silva-Gane M, Marshall C, Warwicker P, Greenwood RN, Farrington K: Survival of elderly patients with stage $5 \mathrm{CKD}$ : comparison of conservative management and renal replacement therapy. Nephrol Dial Transplant 2011;26:1608-1614.
75 Morton RL, Turner RM, Howard K, Snelling P, Webster AC: Patients who plan for conservative care rather than dialysis: a national observational study in Australia. Am J Kidney Dis 2012;59:419-427.

76 Hussain JA, Mooney A, Russon L: Comparison of survival analysis and palliative care involvement in patients aged over 70 years choosing conservative management or renal replacement therapy in advanced chronic kidney disease. Palliat Med 2013;27:829-839.

77 Murtagh FE, Addington-Hall JM, Higginson IJ: End-stage renal disease: a new trajectory of functional decline in the last year of life. J Am Geriatr Soc 2011;59:304-308.

-78 Carson RC, Juszczak M, Davenport A, Burns A: Is maximum conservative management an equivalent treatment option to dialysis for elderly patients with significant comorbid disease? Clin J Am Soc Nephrol 2009;4:16111619.

79 Quill TE, Holloway RG: Evidence, preferences, recommendations - finding the right balance in patient care. N Engl J Med 2012;366: 1653-1655.

80 Schell JO, Patel UD, Steinhauser KE, Ammarell N, Tulsky JA: Discussions of the kidney disease trajectory by elderly patients and nephrologists: a qualitative study. Am J Kidney Dis 2012;59:495-503.

81 Bell D: GMC guidance on end of life care. BMJ 2010;340:c3231.

82 Cohen LM, Ruthazer R, Moss AH, Germain MJ: Predicting six-month mortality for patients who are on maintenance hemodialysis. Clin J Am Soc Nephrol 2010;5:72-79.

83 Murtagh F, Weisbord S: Symptoms in renal disease: their epidemiology, assessment and management; in Chambers E, Brown E, Germain M (eds): Supportive Care for the Renal Patient, ed 2. Oxford, Oxford University Press, 2010, pp 103-132.

84 Davison S, Chamber E, Ferro C: Management of pain in renal failure; in Chambers $\mathrm{E}$, Brown E, Germain M (eds): Supportive Care for the Renal Patient, ed 2. Oxford, Oxford University Press, 2010, pp 139-188.

85 Cukor D, Farrell E, Cohen L, Kimmel P: Psychological and psychiatric considerations in patients with advanced renal disease; in Chambers E, Brown E, Germain M (eds). Supportive Care for the Renal Patient, ed 2. Oxford, Oxford University Press, 2010, pp 189-202.

86 Davies C, Byock I: Spiritual care of the renal patient; in Chambers E, Brown E, Germain M (eds): Supportive Care for the Renal Patient, ed 2. Oxford, Oxford University Press, 2010, pp 203-216. 